\title{
Understanding Roommate Conflict among University of Cape Coast Students: A Poisson Regression Approach
}

\author{
Joyce De-Graft Acquah \\ University of Cape Coast, Cape Coast, Ghana \\ joycedacquah@gmail.com
}

\begin{abstract}
Although roommate conflict and its negative effects are visible on Ghanaian campuses, most of the publications on this type of conflict have been written by scholars in the developed world. Consequently, challenges and consequences associated with this type of conflict in Ghana and developing countries have not been adequately discussed in the literature. This study investigates causes, consequences and management strategies of roommate conflict and willingness to pay for conflict resolution services. Findings of the study indicated that most of the students have had conflict with their roommate. Poor communication, lack of cooperation, unreturned greetings and cold looks were identified as the major forms or signs of conflicts. Respondents indicated main causes of conflicts as refusal to clean room, noise making in the room, gossiping about roommate and using roommate property without permission. With regards to consequences of these conflicts, students suggested feeling tensed and uncomfortable, staying outside their rooms for long hours, sleep distortion and depression to be the major consequences. The study revealed bringing roommate together to resolve conflict themselves, encouraging communication among roommates, negotiation with roommate and special training on developing cooperative attitude among roommate to be the major management strategies to address conflict. Most of the students were unwilling to pay for conflict resolution services if provided by the university. Results of the poison regression estimation suggests family size of student, number of roommates in a room and being in a love relationship as significant and negative predictors of frequency of roommate conflicts.
\end{abstract}

Keywords: Causes, Conflict, Management Strategies, Roommate, Willingness to pay, Poison Regression Model

\section{Introduction}

As social beings, humans construct, maintain and change the social world within which they live. Human life is thus characterized by social relations of dependence and interdependence. However, since each individual is unique and different, differences cannot be totally suppressed from manifesting which increases the potential for conflict whenever people have contact. Conflict is therefore inevitable and thus a normal part of man's social relation (Gillin, 2004). On every university campus, the achievements of institutional and personal goals are also dependent upon the effective and efficient interaction among the individuals. However, a student's experience living in the residential halls with mates can be one of the most rewarding aspects of university life or one of the biggest nightmares which can result in conflict and may be liable to assume alarming proportions if it is not promptly address. In the University of Cape Coast, the residential halls make random matches of roommates for students. The halls of residence are meant to provide interaction beyond the classroom between students assigned as junior members, and academic and senior administrative or professional staff who are assigned tutor from among fellows of the hall. As the numbers of places in the halls now do not match the number of qualified students, non-residence has become a prominent feature of admissions. This has also lead to the introduction of hostels in and around campus. Though students in the University of Cape Coast do experience roommate conflict, the determinants of these conflicts are not well understood. Specifically, the extent to which socio economic characteristics of students influence roommate conflict has not been investigated. In order to assist students to deal with problems of roommate conflict, this study investigates roommate conflict in the University of Cape Coast. Specifically, the objectives of the study are to (1) Describe the socio-economic characteristics of the students (2) Investigate the forms/signs of conflicts (3) Identify causes of roommate conflict (4) Analyze effects of roommate conflict (5) Determine management strategies to address roommate conflict (6) Investigate the willingness to pay for conflict resolution services (7) Determine the socio economic factors that influence roommate conflict. 


\section{Literature Review}

Roommate conflict has been documented in many studies to be a problem for students and continues to pres challenges for residential hall mediation services. Early studies of roommates focused on compatibility and satisfaction (e.g. Carey, Hamilton, \& Shanklin, 1986; Winston \& Yaranovich, 1994). Egwunyenga (2009) investigated the causes and various strategies for managing roommate conflicts in Universities in Nigeria. Results showed that smoking inside the room, using roommates' properties without permission, unacceptable prayer groups activities by some members inside the room, Different cult members in a room with different interests, having an affair with a roommate's lover, competition in the use of electrical appliances before lecture time and refusal of some roommates to settle bills were the major causes of roommate conflict. Also, results showed that to manage conflict and ensure healthy room-mate relationship, belligerent room-mates must be encouraged to communicate and participate in the resolution of conflict. Yadegaran (2013) tackled seven college roommate conflicts. It was found that some of the common causes of roommate conflict were piling up unwashed dishes, incompatible lifestyle such as smoking marijuana and same sex relationships. The study suggested that to resolve room-mate conflict, university staff should be trained in conflict mediation while roommate write formal contract on conduct.

Moving to a college or university is what Vangelisti and Caughlin (1997) label a family stress point. Young adults enter into a time where a significant number of their relationships change. Change causes stress. Stress is known to have deleterious effects on student success (Friedlander, Reid, Shupak, and Cribble, 2007). Stress emerges as the highest barrier to student's success and a major contributor to other negative influences such as fatigue, depression, alcohol use, anxiety and suicidal feelings (McClorkle and Mason, 2009). Further, Chruden and Shermans (1994) opine that, students who experience conflicts feel tensed and uncomfortable, a condition that is commonly referred to as anxiety. According to Hardigg and Nobile (1995), these conflicts in extreme cases lead to serious violence as their research revealed that when there is a problem between roommates and neither can work it out, roommate may start to feel desperate, trapped, and turn the matter into life or death situation. While deaths have been associated with roommate conflicts, Duran and Zakahi (1988) have indicated that poor relationships among students are responsible for dissatisfaction with school and lower Grade Point Average (GPA).

\section{Methodology}

Study Area Description: The University of Cape Coast is the only university in the central region of Ghana and has a total of eight school/faculty. The University has regular students' population of about 15789 students consisting of 10591 males and 5198 females. Residents' students are 6062 while non-residents students are 9727.

Sampling Method and Sample Size: The sample for the study consists of 117 students in the University of Cape Coast. The population for the study was all students in the university of Cape Coast. Multistage random sampling technique was used to select respondents of study. The first stage involved random sampling of seven (7) residential halls namely Casely Hayford hall, Valco hall, Kwame Nkrumah hall, Oguaa hall, Adehye hall, Atlantic hall and the Students Representative Council hostel. Fifteen (15) respondents were selected from each of the halls except Adehye hall which is an all female hall and Casely Hayford hall which is an allmale hall with twenty-one (21) respondents each. This was due to the fact that same gender is prone to conflict especially females.

Data collection and Analysis: An interview schedule was the main tool of data collection while descriptive statistics and regression analysis were the main analytical techniques. Data was analyzed using Statistical Product and Service Solution (SPSS) version 15.0 and R programming Language. Results of the study were presented in tables and bar charts whilst frequencies and percentages were used to discuss the results.

Poisson Regression Modeling: Suppose that we have a sample of $\mathrm{n}$ observations $\mathrm{y}_{1}, \mathrm{y}_{2} \ldots \ldots \ldots . . . . \mathrm{y}_{\mathrm{n}}$ which can be treated as realizations of independent Poisson random variables, with the expectation of the response variable following a Poisson distribution and dependent on a vector of explanatory variables, $x \in \mathbb{R}^{n}$. A simple linear model of the form below could be entertained: 
$u_{i}=\mathrm{E}(Y \mid x)=\theta^{\prime} x$

However, this model has the disadvantage that the linear predictor on the right hand side can assume any real value, whereas the Poisson mean on the left hand side, which represents an expected count, has to be non-negative. A straightforward solution to this problem is to model instead the logarithm of the mean using a linear model. In effect a generalized linear model with linear log is considered and the log-linear model written as:

$$
\log (\mathrm{E}(Y \mid x))=\theta^{\prime} x
$$

In this model the regression coefficient $\beta_{\mathrm{j}}$ represents the expected change in the log of the mean per unit change in the predictor $\mathrm{x}_{\mathrm{j}}$. In other words increasing $\mathrm{x}_{\mathrm{j}}$ by one unit is associated with an increase of $\beta_{\mathrm{j}}$ in the $\log$ of the mean. Exponentiating the above equation we obtain a Poisson model for the mean:

$\mathrm{E}(Y \mid x)=e^{\theta^{\prime} x}$

In this model, an exponentiated regression coefficient $\exp \left\{\beta_{\mathrm{j}}\right\}$ represents a multiplicative effect of the $\mathrm{j}$-th predictor on the mean. Increasing $\mathrm{x}_{\mathrm{j}}$ by one unit multiplies the mean by a factor $\exp \left\{\beta_{\mathrm{j}}\right\}$. If $Y_{i}$ are independent_observations with corresponding values $x_{i}$ of the predictor variable, then $\theta$ can be estimated by maximum likelihood.

Maximum likelihood-based parameter estimation: Given a set of parameters $\theta$ and an input vector $x$, the mean of the predicted Poisson distribution, as stated above, is given by

$\mathrm{E}(Y \mid x)=e^{\theta^{\prime} x}$

and thus, the Poisson distribution's probability mass function is given by

$p(y \mid x ; \theta)=\frac{e^{y\left(\theta^{\prime} x\right)} e^{-e^{\theta^{\prime} x}}}{y !}$

Suppose we are given a data set consisting of $m$ vectors $x_{i} \in \mathbb{R}^{n+1}, i=1, \ldots, m$, along with a set of $m$ values $y_{1}, \ldots, y_{m} \in \mathbb{R}$. Then, for a given set of parameters $\theta$, the probability of attaining this particular set of data is given by

$p\left(y_{1}, \ldots, y_{m} \mid x_{1}, \ldots, x_{m} ; \theta\right)=\prod_{i=1}^{m} \frac{e^{y_{i}\left(\theta^{\prime} x_{i}\right)} e^{-e^{\theta^{\prime} x_{i}}}}{y_{i} !}$.

By the method of maximum likelihood estimation, we wish to find the set of parameters $\theta$ that makes this probability as large as possible. To do this, the equation is first rewritten as a likelihood function in terms of $\theta$ :

$$
L(\theta \mid X, Y)=\prod_{i=1}^{m} \frac{e^{y_{i}\left(\theta^{\prime} x_{i}\right)} e^{-e^{\theta^{\prime} x_{i}}}}{y_{i} !} .
$$

Noticeably, the expression on the right hand side has not actually changed. A formula in this form is typically difficult to work with; instead, one uses the log-likelihood:

$$
\ell(\theta \mid X, Y)=\log L(\theta \mid X, Y)=\sum_{i=1}^{m}\left(y_{i}\left(\theta^{\prime} x_{i}\right)-e^{\theta^{\prime} x_{i}}-\log \left(y_{i} !\right)\right)
$$

The parameters $\theta$ only appear in the first two terms of each term in the summation. Therefore, given that we are only interested in finding the best value for $\theta$ we may drop the $y_{i}$ ! and simply write the log-likelihood function as:

$$
\ell(\theta \mid X, Y)=\sum_{i=1}^{m}\left(y_{i}\left(\theta^{\prime} x_{i}\right)-e^{\theta^{\prime} x_{i}}\right)
$$




\section{Results and Discussion}

Socio-economic Characteristics of Respondents: In an attempt to investigate the socio economic characteristics, respondents were asked questions pertaining to that. Of the respondents interviewed, the males constitute $49.6 \%$ while the remaining $50.4 \%$ were females. Up to $47.9 \%$ of the respondents interviewed were between the ages of $18-20$ years; $23.1 \%$ were between $21-22$ years; $7.7 \%$ were between 23-24 years, 9.4\% were between $25-26$ years, $7.7 \%$ were between $27-28$ years, only $1.7 \%$ were between 29 30 years, and 2.6\% were between 33-34years. Most of the respondents (70.1\%) were Akans (consisting of Fante, Asante, Akyem, Kwahu and Nzema), 12\% were Ewes, $4.3 \%$ were Ga- Adangbe (consisting of Ga and Krobo), 1.7\% were Kusasi, Dagomba, Mamprusi, Gonja, Guan, and Frafra each. Wassa and Sissala constituted $0.9 \%$ each. Of the respondents interviewed, up to $93.2 \%$ were Christians with Muslims constituting only $6.8 \%$. When asked if respondents had some of their roommates belonging to different religion other than theirs, only $26.5 \%$ of respondents answered in the affirmative while up to $73.5 \%$ were contrary to this view. Most of the respondents constituting 79.5\% had resided in boarding houses prior to entering the university. Of the respondents interviewed, only 3.4\% had household size between 0-3 persons, majority of the respondents consisting $61.5 \%$ had between $4-6$ persons, and $29.9 \%$ had between $7-9$ persons and only $5.1 \%$ had household size between $10-12$ persons. $38.5 \%$ of the respondents had obtained 16 years of education, $17.9 \%$ had obtained 17 years of education, $19.7 \%$ had obtained 18 years of education, $17.9 \%$ had obtained 19 years of education, $4.3 \%$ had obtained 20 years of education and only $1.7 \%$ had obtained 21 years of education. When respondents were asked how many siblings they had, $31.6 \%$ had between $0-2$ siblings, 45.3\% had between 3-4 siblings, $17.1 \%$ had between 5-6 siblings, $5.1 \%$ had between $7-8$ siblings with only one $(0.9 \%)$ respondent having $9-10$ siblings. $47 \%$ of the respondents had monthly remittance of $<\mathrm{GH} \$ 100$, $41.9 \%$ had monthly remittance between $\mathrm{GH} \$ 101-200$, with the remaining $11.1 \%$ of the respondents receiving monthly remittance between $\mathrm{GH} \$ 201-500$.

\section{Figure 1: Forms or Signs of Conflicts}

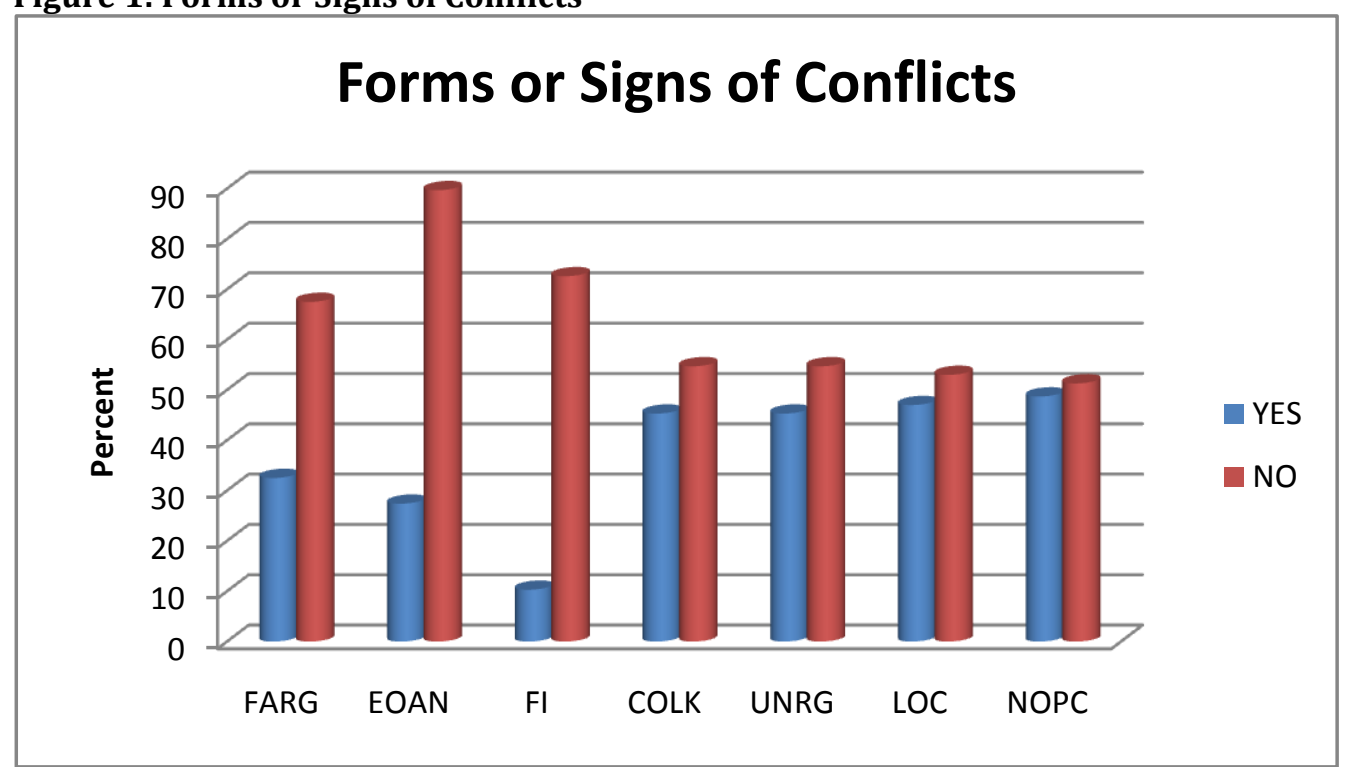

Note: $\mathbf{F A R G}=$ Furious Argument, EOAN $=$ Exchange of Angry Notes, $\mathbf{F I}=$ Fight, $\mathbf{C O L K}=$ Cold Look, UNRG= Unreturned Greeting, LOC= Lack of Cooperation, NOPC= No or Poor Communication

The study investigated the forms of conflict encountered by students of the University of Cape Coast. When asked if respondents have had any form of conflict with their past and present roommates, $63.2 \%$ of them indicated that they have had conflicts while the remaining $36.8 \%$ had maintained a cordial relationship with their roommates. Major forms or signs of conflicts included no or poor communications, lack of cooperation, cold look and unreturned greeting. 48.7\% of the respondents indicated no or poor communication as a sign of conflict while the $51.3 \%$ did not. With regards to lack of cooperation, $47 \%$ of the total respondents indicated as a sign of conflict. Unreturned greetings and cold looks had $45.3 \%$ each. About $32.5 \%$ indicated furious 
argument as a sign or form of conflict while $67.5 \%$ opined differently. $27.4 \%$ exchanged angry notes as a form of conflict while $72.6 \%$ did not indicate that as a form of conflict. Only $10.3 \%$ of the respondents indicated fight as a form of conflict while up to $89.7 \%$ were contrary to this opinion.

Causes of Roommate Conflict: The causes of roommate conflict were investigated. The results revealed the major causes of conflict among roommates to be refusal to clean room by some roommates, making noise in the room, gossiping about fellow roommate, using roommate property without permission and bringing many friends to the room more than what roommate can tolerate.

Figure 2: Causes of Roommates Conflict

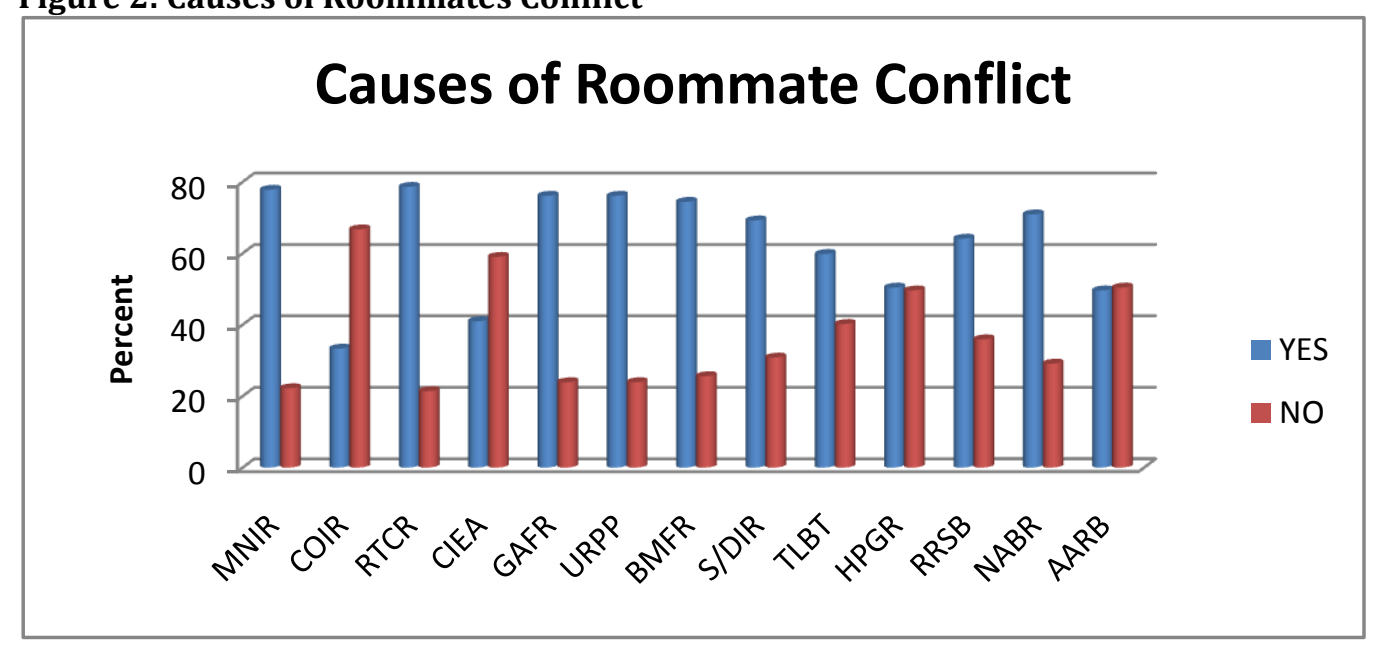

Note: MNIR= Making noise in the room, COIR= Cooking in the room, RTCR= Refusal to clean room, CIEA= Competition in the use of electrical appliances, GAFR= gossiping about fellow roommate, URPP=Using roommate property without permission, BMFR= Bringing many friends to the room, $\mathrm{S} / \mathrm{DIR}=$ Smoking/drinking in the room, TLBT= Turning on light during bed time, HPGR= Having prayer group activities in the room, RRSB= Refusal of some roommates to settle bills, NABR= Narrowing by some roommates, $\mathrm{AARB}=$ Arguments about religious beliefs.

Of the respondents interviewed, $77.8 \%$ indicated that roommate conflict was as a result of making noise in the room while the $22.2 \%$ were contrary to this view. Only $33 \%$ blamed cooking in the room as a cause of conflict while up to $66.7 \%$ opined differently. Refusal to clean room also saw many respondents $(78.6 \%)$ indicating it as a cause of conflict while the remaining $21.4 \%$ were of different opinion. $41 \%$ indicated competition in the use of electrical appliances as a cause of conflict. Up to $76.1 \%$ of the respondents indicated that gossiping about fellow roommate and using roommate property without permission were each a cause of roommate conflict. $74.4 \%$ of the respondents indicated bringing too many friends to the room to be a cause of conflict. $69.2 \%$ of the respondents indicated that smoking/drinking in the room as a cause of conflict while the remaining $30.8 \%$ opined differently. Turning on light during bed time was also a cause of conflict as indicated by $59.8 \%$ of respondents while the remaining $40.2 \%$ were of contrary view. $50.4 \%$ of the respondents indicated that having prayer group activities in the room causes conflict while $49.6 \%$ were contrary to this view. $64.1 \%$ of the respondents indicated that refusal of some roommates to settle utility bills causes conflicts while the remaining $35.9 \%$ had different opinion. Up to $70.9 \%$ of the respondents indicated bringing boyfriends and girlfriends ("narrowing") by some roommates into the room causes conflicts while the remaining $29.1 \%$ opined differently. Of the respondents interviewed, $49.6 \%$ indicated that arguments about religious beliefs causes conflict among roommate.

Consequences of Roommates Conflict: The study investigated the consequences of roommate conflicts on students. Major effects of conflicts on students were identified by respondents as feeling tensed and uncomfortable in the room, students staying outside their rooms for long hours, sleep distortion and depression. 
Figure 3: Effect of Roommates Conflict

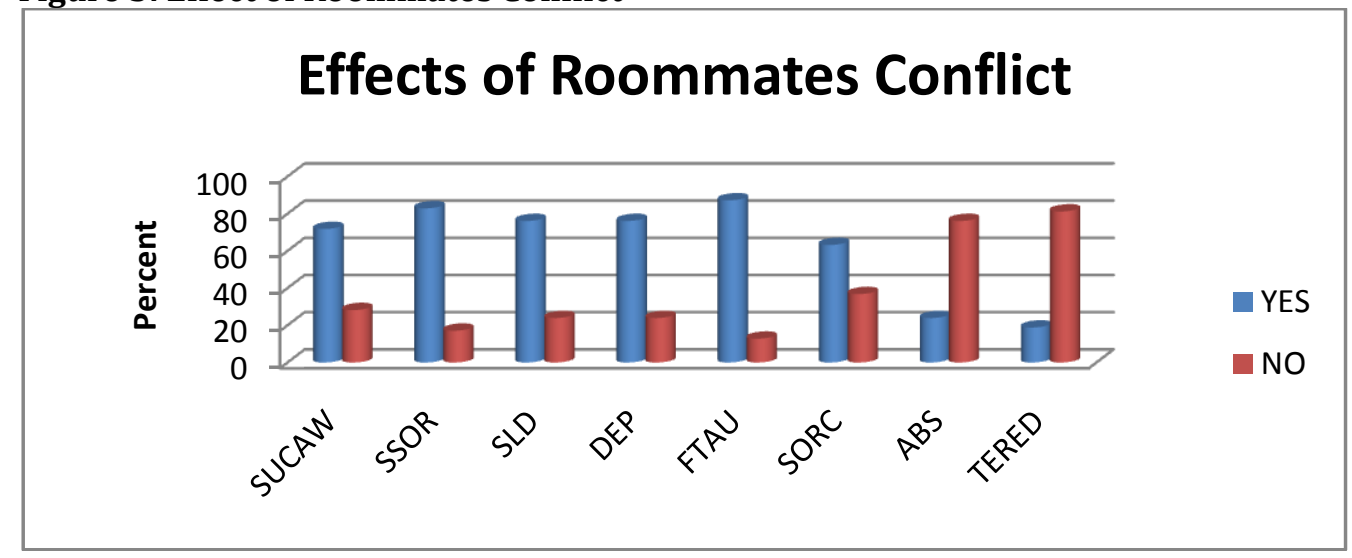

Note: SUCAW= Students are unable to concentrate on academic work, SSOR= Students stay outside the room for long hours, $\mathrm{SLD}=$ Sleep distortion, $\mathrm{DEP}=$ Depression, $\mathrm{FTAU}=$ Feeling tensed and uncomfortable, SORC= Stereotyping others based on roommate characteristics, $\mathrm{ABS}=$ Absenteeism and TERED $=$ Terminate education

Of the respondents interviewed, $71.8 \%$ indicated students are unable to concentrate on academic work as an effect of conflict while the remaining $28.2 \%$ did not support this assertion. $82.9 \%$ indicated students stay outside the room for long hours while the remaining $17.1 \%$ opined differently. $76.1 \%$ of the respondents each indicated sleep distortion and depression to be effect of conflict while the remaining $23.9 \%$ were of contrary view. Up to $87.2 \%$ indicated students feel tensed and uncomfortable as an effect of conflict while only $12.8 \%$ opined differently. $63.2 \%$ of the respondents indicated that roommate conflict leads to stereotyping others based on roommate characteristics while the remaining 36.8\% did not support this assertion. Only $23.9 \%$ indicated absenteeism to be an effect of conflict while up to $76.1 \%$ were of a contrary view. $18.8 \%$ of the respondents supported termination of education as a consequence of roommate conflict while up to $81.2 \%$ did not support this assertion.

Management Strategies to Address Roommate Conflict: The study investigated management strategies employed by students to deal with roommate conflict. The results revealed bringing roommates together to solve their own conflict, encouraging communication among roommate and negotiation with roommate and special training on developing cooperative attitude among roommates as the major management strategy to address roommate conflict.

Figure 4: Management Strategies to Address Roommate Conflict

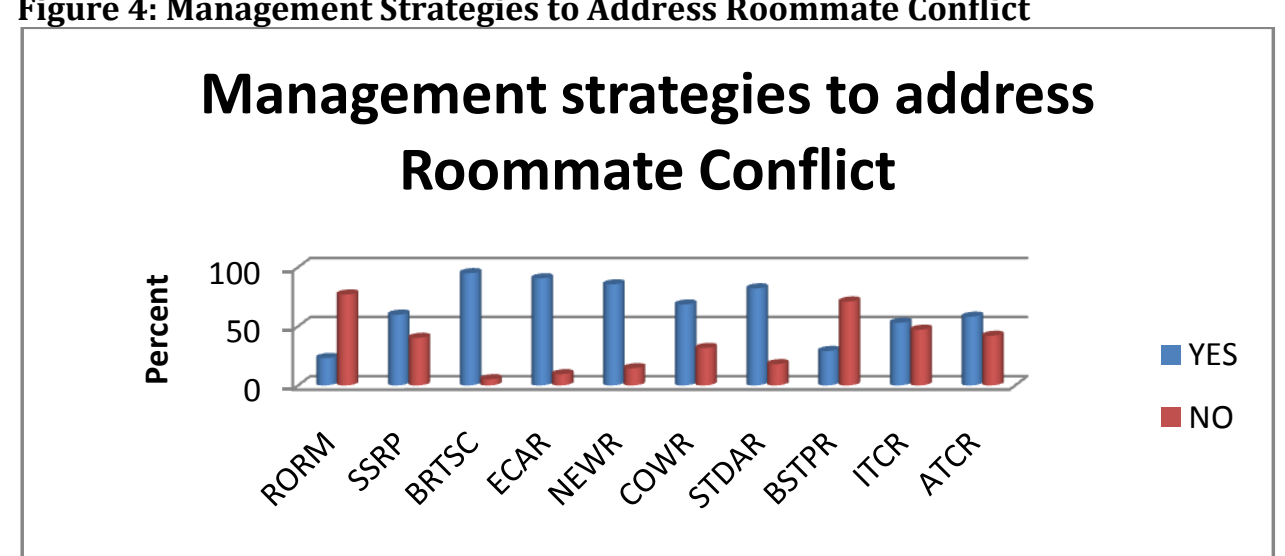

Note: RORM=Rotating roommate, SSRP $=$ Setting stringent rules and punishment, $\mathrm{BRTSC}=$ Bringing roommates together to solve conflicts, $\mathrm{ECAR}=$ Encouraging communication among roommate, NEWR= Negotiation with roommates, COWR= Confrontation with roommate, STDAR= Special training on developing 
cooperative attitude among roommates, BSTPR= Bringing a student as a third party to settle issues ITCR= Introducing topics on conflict resolution as a course, ATCR= Ability to choose roommate

The results revealed that out of the total $100 \%$ (117 respondents) each, only $23.1 \%$ of the respondents indicated rotating roommates as a strategy to manage a conflict. Setting stringent rules and punishment attracted $59.8 \%$ of the respondents indicating it as a conflict management strategy. Up to $94.9 \%$ indicated bringing roommates together to solve conflict as an effective conflict management strategy. $90.6 \%$ of the respondents interviewed indicated encouraging communication among roommate as a management strategy. Negotiation with roommates attracted $85.5 \%$ of respondents indicating as management strategy. About $68.4 \%$ of respondents indicated confrontation with roommate as a strategy to address conflict. Other effective management strategies indicated are as follows. $82.1 \%$ of the respondents interviewed indicated special training on developing cooperative attitude among roommates, $29.1 \%$ indicated bringing a student as a third party to settle issues, 53\% indicated introducing topics on conflict resolution as a course while 58.1\% indicated ability to choose roommate as effective management strategy to address roommate conflicts.

Willingness to Pay for Conflict Resolution Service: Analysis of the students' willingness to pay (WTP) for conflict resolution services as shown in Table (1) revealed a mean willingness of GH\$ 1.86 with a standard deviation of GH $\$ 3.23$. However, majority of the respondents were not willing to pay representing a median of $\mathrm{GH} \$ 0.00$. Among those willing to pay, very few were willing to pay higher amounts; hence the distribution is skewed by a limited number of higher bidders.

Table 1: The Statistics of Willingness to Pay (WTP)

\begin{tabular}{lc} 
Mean (Std. Deviation 3.23) & 1.86 \\
Median & .00 \\
Skewness ( Std. Error of Skewness) & 1.69 \\
Kurtosis & 1.53 \\
Std. Error of Kurtosis & .44 \\
\hline
\end{tabular}

When respondents were asked if they were willing to pay for conflict resolution services if provided in the University, only $37.6 \%$ indicated yes while up to $63.2 \%$ indicated unwillingness to pay. Of the amount willing to pay, $\mathrm{GH} \$ 1, \mathrm{GH} 4$, GH\$ 5 and $\mathrm{GH} \$ 10$ were the most popular responses.

\section{Table 2: The frequency of the bids of WTP}

\begin{tabular}{lcc}
\hline Bids of WTP (GHd) & Frequency & Percent \\
\hline 0 & 74 & 63.2 \\
1 & 9 & 7.7 \\
2 & 7 & 6.0 \\
4 & 1 & 0.9 \\
5 & 13 & 11.1 \\
6 & 1 & 0.9 \\
10 & 12 & 10.3 \\
\hline Total & 117 & 100.0 \\
\hline
\end{tabular}

Zero indicates that the respondents were not willing to pay. Respondents suggested that rather than paying, the Student Representative Council dues should cater for conflict resolution services among roommate. Furthermore, conflicting roommates should be made to pay since not everyone indulges him/herself in roommate conflict.

Model Estimation Results of the Poisson Regression Analysis: A poisson regression analysis was employed to analyze the socio-economic factors that influence roommate conflict. The Akaike Information Criteria (Akaike, 1973), provided the basis for selecting the model that provided the best fit to the conflict data. The model specification with frequency of roommate conflict as the dependent variable and gender, age, family size, roommates of different religion, prior experience in a boarding house, number of roommates one has, years of education, being in a love relationship, number of sibling and remittance as the covariates 
provided the best fit with AIC of 581.2. Result shows that family size, prior experience in a boarding house, Number of roommates one has, years of education, involvement in a love relationship and number of sibling exhibit statistically significant association with the frequency of roommate conflicts. The model estimation result reveals a significantly negative relationship between frequency of conflicts and the regression covariates (i.e. family size, number of roommates one has and being in a love relationship). A significantly positive relationship exists between frequency of conflicts and the regression covariates (i.e. prior experience in a boarding house and number of Sibling).

Table 3: Parameter estimates of the Poisson Model

\begin{tabular}{lllll}
\hline Variables & Estimates & Std. Error & z value & Pr ( I z I) \\
\hline Intercept & -1.539 & 1.038 & -1.482 & 0.138 \\
GEN & 0.167 & 0.170 & 0.980 & 0.327 \\
AGE & 0.027 & 0.028 & 0.945 & 0.344 \\
FSIZE & -0.263 & 0.099 & -2.648 & $0.008^{* *}$ \\
DIFR & 0.038 & 0.176 & 0.218 & 0.827 \\
BOD & 0.591 & 0.204 & -2.908 & $0.003^{* *}$ \\
NRM & -0.119 & 0.048 & -2.497 & $0.012^{*}$ \\
EDU & 0.107 & 0.068 & 1.576 & 0.115 \\
LOR & -0.381 & 0.148 & -2.573 & $0.010^{*}$ \\
NOS & 0.333 & 0.097 & 3.437 & $0.0005^{* * *}$ \\
REM & 0.0002 & 0.0002 & 0.919 & 0.358 \\
\hline
\end{tabular}

Significance. codes: 0 '***’ $0.001^{\text {(**) }} 0.01^{\text {'*’ }} 0.05$ '? $0.1^{\prime \prime} 1$

NOTE: GEN= gender, AGE= age, FSIZE= family size, DIFR= Roommates of different religion, $\mathrm{BOD}=$ Prior experience in a boarding house, $\mathrm{NRM=} \mathrm{Number}$ of roommates one has, EDU= years of education, LOR= Being in a love relationship, NOS= Number of Sibling and REM= Remittance

It should be emphasized that a negative sign of a parameter indicates that high values of the variables tend to decrease the frequency of conflict. A positive sign implies that high values of the variables will increase the frequency of conflict. In effect the frequency of roommate conflict decreases with family size, number of roommates one has and being in a love relationship.

\section{Conclusion}

Conflicts among roommates are inevitable because of the diverse backgrounds of students creating a potentially volatile mixture of values, customs, religion, expectations and sensibilities in the rooms. A survey of 117 randomly sampled students from all the halls of the University of Cape Coast was conducted using a standard questionnaire. An interview schedule was the main tool of data collection while descriptive statistics and poison regression analysis were the main analytical techniques. The objectives of the study were to (1) Describe the socio-economic characteristics of the students (2) Investigate the forms/signs of conflicts (3) Identify causes of roommate conflict (4) Analyze effects of roommate conflict (5) Determine management strategies to address roommate conflict (6) Investigate the willingness to pay for conflict resolution services. (7) Determine the socio economic factors that influence roommate conflict. Findings show that most of the students have had conflict with their roommates. Poor communication, lack of cooperation, unreturned greetings and cold looks were identified as the major forms of conflicts. Respondents indicated major causes of conflicts as refusal to clean room, noise making in the room, gossiping about roommate and using roommate property without permission. With regards to consequences of these conflicts, students suggested feeling tensed and uncomfortable, staying outside their rooms for long hours, sleep distortion and depression to be the major consequences. Findings of the study also suggest bringing roommate together to solve conflict, encouraging communication among roommates, negotiation with roommate and special training on developing cooperative attitude among roommate to be the major management strategies to address conflict. Most of the students were unwilling to pay for conflict resolution services if provided by the University. The major reasons for unwillingness to pay were that the Student Representative Council dues should cater for conflict resolution among roommates and conflicting roommates should be the ones made to pay since not every student indulges in roommate conflict. Results 
from the poison regression estimation suggests family size of student, number of roommates in a room and being in a love relationship as significant and negative predictors of frequency of roommate conflicts. Implications for policy are that university authorities should take socio economic characteristics of students into account when assigning roommates.

\section{References}

Akaike, H. (1973). Information theory and an extension of the maximum likelihood principle. In: Petrov, B.N. and Csaki, F. (eds.) 2 $2^{\text {nd }}$ International symposium on information theory: 267-81 Budapest. Akademiai Kiado.

Carey,J. C., Hamilton, D. L. \& Shanklin, G. (1986). Development of an Instrument to Measure Rapport between College Roommates. Journal of College Students Personnel, 27, 269-273.

Chruden, H. J. \& Sherman, A. W. (1994). Managing Human Resources. Dallas: South-western Publishing Company.

Duran, R. L. \& Zakahi, W. R. (1988). The Influence of Communicative Competence upon Roommate Satisfaction. Western Journal of Speech Communication, 52, 135-146.

Egwunyenga, E. J. (2009). Room-Mates Conflicts in Nigerian Universities: Causes and Management Strategies. Kamal-Raj Journal of Social Sciences, 27(2), 123-127.

Friedlander, L. J., Reid G. J., Shupak, N. \& Cribbie, R. (2007). Social Support, Self-esteemed, and Stress as Predictors of Adjustment to University among First-year Undergraduates. Journal of College Student Development, 48(3), 259-274.

Gillin, C. T. (2004). Conflict Resolution, Negotiation \& Team Building: Reviewing an Impossible Course that Worked. Conflict Management in Higher Education Report, 5(1).

Hardigg, V. \& Nobile, C. (1995). Living with a Stranger. U.S. News \& World Report, 119(12), 90.25 Jan., 2009.

McClorkle, S. \& Mason-Susan, G. (2009). Conflict in Residence Halls: A Preliminary Study of the Efficacy of Roommates Negotiations to Reduce Roommate Conflict. Boise State University.

Vangelisti, A. L. \& Caughlin, J. P. (1997). Reveling Family Secretes. The Influence of Topic Function and Relationship. Journal of Social and Personal Relationships, 14(5), 679-368.

Winston, Jr., R. B. \& Yaranovich, M. F. (1994). Quality of Roommate Relationships: Development of the Roommate Relationship Inventory. Journal of College and University Student Housing, 24, 6-11.

Yadegaran, J. (2013). Seven College Roommate Conflicts and Solutions: Contra Costa Times (Walnut Creek, CA), Aug 13, 2013. 